\title{
Thermodynamic Analysis of Bus Air Conditioner Working with Refrigerant R600a
}

\author{
Mehmet Bilgili' ${ }^{*}$, Ediz Cardak', Arif Emre Aktas'
}

${ }^{1}$ Cukurova University, Automotive Engineering Department, Turkey

\begin{abstract}
Refrigerant R134a (tetrafluoroethane) is widely used in automotive air conditioners and has a good performance. However, since refrigerant R134a still has a high global warming potential (GWP), this refrigerant must be replaced with environmentally friendly refrigerants such as R600a (isobutane), which is a natural fluid, no effect on the climate, inexpensive and readily available. In this study, thermodynamic analysis of a bus air conditioner working with refrigerant R600a was performed. Adana province of Turkey was chosen as the study region. Firstly, a bus used for inter-city passenger transportation with a passenger capacity of 56 persons was selected. Cooling Load Hourly Analysis Program (HAP) was used to determine the hourly cooling load capacity of the selected inter-city bus model. Useful and reversible works of compressor, coefficient of performance (COP), exergy efficiency and exergy destructions of the bus air conditioning system were obtained and evaluated in detail.
\end{abstract}

Keywords: Air-conditioning, refrigerant R600a, air mixing ratio, exergy, exergy efficiency, intercity bus.

\section{INTRODUCTION}

Today, the development of industrialization and technology has brought many advantages, such as efficient production, cheaper price and thus improved quality of life. On the other hand, global energy demand has shown a significant increase due to rising technological and population growth, and at the same time, unfortunately, fossil fuels have been sharply declining. In this respect, the global warming being the threat of climatic change, efficient usage of energy sources and greenhouse-gas (GHG) emissions based on fossil energy consumption have become most attractive issues in the present decade [1].

With steady temperature increase throughout the years, the importance of air-conditioning (AC) systems is becoming more important part of our lives day by day. AC systems have great importance in transportation as well. The comfort of the passengers is as important as the energy efficiency of vehicles. An ideal automobile air-conditioning (AAC) system reduces temperature and humidity which can impact on our thermal comfort and air quality. The system also reduces dehydration level and thus excessive sweating [2]. The importance of AC becomes clearer, especially when hot temperatures being experienced. On the other hand, AAC systems and most of their components, regardless of their benefits, consume great amounts of energy.

The number of buses and total vehicles is increasing rapidly in Turkey and the world. With growing numbers of vehicles, energy efficiency becomes more important in public transportation. It is worthwhile to mention that buses are one of the most important figures of public transportation and they are designed to carry many passengers. Automotive air conditioning (AAC) systems are the second largest energy consumers in vehicles including buses [3]. To reduce fuel consumption of an inter-city bus, increasing the energy efficiency of inter-city bus AC system should bee taken into consideration.

There are several available refrigerants for AC systems. R404a, R410a, R502, R507, R22, R290, R134a, R500 and, $\mathrm{R} 600 \mathrm{a}$ refrigerants are some of them. Refrigerant R134a (tetrafluoroethane) is widely used in automotive air conditioners and has good performance. However, since refrigerant R134a still has a high global warming potential (GWP), this refrigerant must be replaced with environmentally friendly refrigerants such as R600a (isobutane), which is a natural fluid, no effect on the climate, inexpensive and readily available. In this study, thermodynamic analysis of bus air conditioner working with refrigerant R600a was performed. Total exergy destruction and overall exergy efficiency of system were obtained and evaluated in detail.

${ }^{*}$ Corresponding authour

Email: mbilgili@cu.edu.tr (M. Bilgili) 


\section{MATERIAL AND METHODS}

A schematic view of the inter-city bus AC system is presented in Figure 1. As seen from the figure, the outside fresh air is firstly mixed with re-circulated air to satisfy the ventilation requirement. Then, the mixed air flows through a cooling coil (evaporator), and it is supplied to the cabin by the evaporator fan. Standard inter-city bus AC system components are compressor, evaporator, expansion valve and condenser.

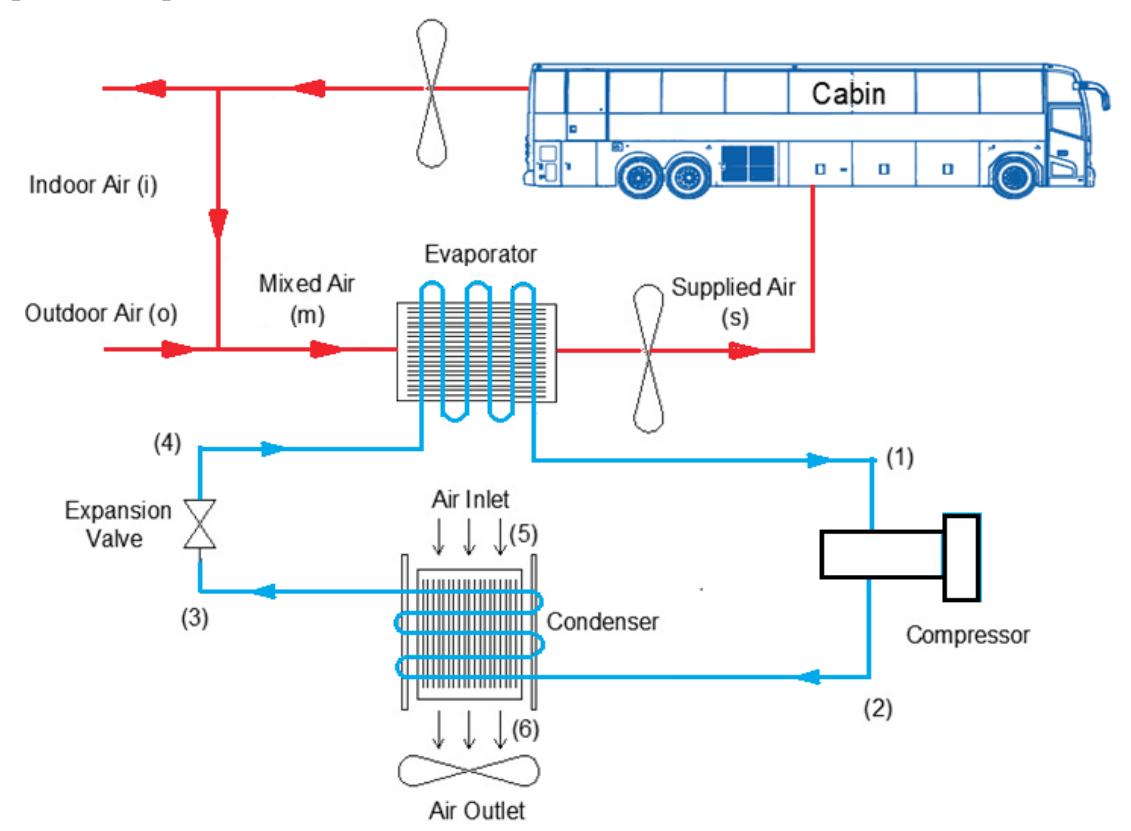

Figure 1. Schematic view of the inter-city bus AC system

The mass flow rate of outdoor air, $\dot{\mathrm{m}}_{\mathrm{o}}$, and the mass flow rate of indoor air, $\dot{\mathrm{m}}_{\mathrm{j}}$, are mixed at a constant pressure and certain rate. The value of air mixing ratio, $M R$ is defined by:

$$
\mathrm{MR}=\frac{\dot{\mathrm{m}}_{\mathrm{o}}}{\dot{\mathrm{m}}_{\mathrm{j}}}
$$

From the mass balance of dry air and water vapor:

$$
\begin{aligned}
& \dot{\mathrm{m}}_{\mathrm{s}}=\dot{\mathrm{m}}_{\mathrm{o}}+\dot{\mathrm{m}}_{\mathrm{i}}=\dot{\mathrm{m}}_{\mathrm{m}} \\
& \dot{\mathrm{m}}_{\mathrm{m}} \cdot \mathrm{w}_{\mathrm{m}}=\dot{\mathrm{m}}_{\mathrm{o}} \cdot \mathrm{w}_{\mathrm{o}}+\dot{\mathrm{m}}_{\mathrm{i}} \cdot \mathrm{w}_{\mathrm{i}}
\end{aligned}
$$

From the energy balance:

$$
\dot{\mathrm{m}}_{\mathrm{m}} \cdot \mathrm{h}_{\mathrm{m}}=\dot{\mathrm{m}}_{\mathrm{o}} \cdot \mathrm{h}_{\mathrm{o}}+\dot{\mathrm{m}}_{\mathrm{i}} \cdot \mathrm{h}_{\mathrm{i}}
$$

The sensible cooling load, $\dot{\mathrm{Q}}_{\text {sensible,bus }}$, and the latent cooling load, $\dot{\mathrm{Q}}_{\text {latent,bus }}$, on the inter-city bus are given by:

$$
\begin{aligned}
& \dot{\mathrm{Q}}_{\text {sensible,bus }}=\dot{\mathrm{m}}_{\mathrm{s}} \cdot \mathrm{c}_{\mathrm{p}} \cdot\left(\mathrm{T}_{\mathrm{i}}-\mathrm{T}_{\mathrm{o}}\right) \\
& \dot{\mathrm{Q}}_{\text {latent,bus }}=\dot{\mathrm{m}}_{\mathrm{s}} \cdot \mathrm{h}_{\mathrm{fg}} \cdot\left(\mathrm{w}_{\mathrm{i}}-\mathrm{w}_{\mathrm{o}}\right)
\end{aligned}
$$

By-pass factor, BPF can be calculated as:

$$
\mathrm{BPF}=\frac{\mathrm{T}_{\mathrm{s}}-\mathrm{T}_{\mathrm{ADP}}}{\mathrm{T}_{\mathrm{m}}-\mathrm{T}_{\mathrm{ADP}}}
$$

where $T_{s}, T_{A D P}$ and $T_{m}$ are the supplied air temperature, the coil apparatus dew-point temperature and the mixed air temperature, respectively. The optimum capacity of the cooling coil, $\dot{\mathrm{Q}}_{\text {evaporator }}$, can be obtained from energy balance across the cooling coil [4]: 


$$
\dot{\mathrm{Q}}_{\text {evaporator }}=\dot{\mathrm{m}}_{\mathrm{s}} \cdot\left(\mathrm{h}_{\mathrm{m}}-\mathrm{h}_{\mathrm{s}}\right)-\dot{\mathrm{m}}_{\mathrm{w}} \cdot \mathrm{h}_{\mathrm{w}}
$$

where $\mathrm{h}_{\mathrm{w}}$ and $\dot{\mathrm{m}}_{\mathrm{w}}$ are the enthalpy of condensate leaving the cooling coil (evaporator) and mass flow rate of condensate on the cooling coil, respectively. $\dot{\mathrm{m}}_{\mathrm{w}}$ can be calculated as follows:

$$
\dot{\mathrm{m}}_{\mathrm{w}}=\dot{\mathrm{m}}_{\mathrm{s}} \cdot\left(\mathrm{w}_{\mathrm{m}}-\mathrm{w}_{\mathrm{s}}\right)
$$

The general exergy balance is written as:

$$
\dot{\mathrm{Ex}} \mathrm{in}_{\mathrm{in}}-\dot{\mathrm{Ex}} \mathrm{out}_{\mathrm{e}}=\dot{\mathrm{Ex}} \mathrm{dest}
$$

where $\dot{\mathrm{E}} \mathrm{x}_{\text {in }}-\dot{\mathrm{E}} \mathrm{x}_{\text {out }}$ is the rate of net exergy transfer by work, heat and mass. Moreover, the rate of net exergy destruction is indicated with $\dot{\mathrm{E}} \mathrm{x}_{\text {dest }}$ in the equation above. The general exergy balance can also be written in the rate form as [5]:

$$
\dot{\mathrm{E}} \mathrm{x}_{\text {heat }}-\dot{\mathrm{E}} \mathrm{x}_{\text {work }}+\dot{\mathrm{E}} \mathrm{x}_{\text {mass,in }}-\dot{\mathrm{E}} \mathrm{x}_{\text {mass,out }}=\dot{\mathrm{E}} \mathrm{x}_{\text {dest }}
$$

Besides, the rate of formation of the general exergy balance is evaluated as:

$$
\sum\left(1-\frac{\mathrm{T}_{0}}{\mathrm{~T}_{\mathrm{k}}}\right) \cdot \dot{\mathrm{Q}}_{\mathrm{k}}-\dot{\mathrm{W}}+\sum\left(\dot{\mathrm{m}}_{\mathrm{in}} \cdot \mathrm{ex}_{\mathrm{in}}\right)-\sum\left(\dot{\mathrm{m}}_{\text {out }} \cdot \mathrm{ex}_{\text {out }}\right)=\dot{\mathrm{Ex}}_{\text {dest }}
$$

where and are the work rate and the flow (specific) exergy, respectively. Additionally, the properties at the reference (dead) state of $\mathrm{P}_{0}$ and $\mathrm{T}_{0}$ are shown as subscript zero. The specific flow exergy of refrigerant or air can be calculated from the following equation:

$$
\mathrm{ex}_{\text {ref,air }}=\left(\mathrm{h}-\mathrm{h}_{0}\right)-\mathrm{T} \cdot\left(\mathrm{s}-\mathrm{s}_{0}\right)
$$

The exergy rate is calculated as:

$$
\dot{\mathrm{Ex}}=\dot{\mathrm{m}} \cdot(\mathrm{ex})
$$

The exergy efficiency of various steady-flow devices, $\psi$, can also be expressed as:

$$
\psi=\frac{\dot{\mathrm{E}} \mathrm{x}_{\text {out }}}{\dot{\mathrm{E}} \mathrm{x}_{\text {in }}}=\frac{\text { Exergy recovered }}{\text { Exergy supplied }}
$$

$\mathrm{COP}_{\text {ref }}$ which is an energy-based efficiency measure of the refrigeration unit is calculated from the following equation:

$$
\mathrm{COP}_{\text {ref }}=\frac{\dot{\mathrm{Q}}_{\text {evap }}}{\dot{\mathrm{W}}_{\text {comp }}}
$$

The reversible power, $\dot{\mathrm{W}}_{\text {rev }}$, can be defined as:

$$
\dot{\mathrm{W}}_{\text {rev }}=\dot{\mathrm{W}}_{\text {comp }}-\dot{\mathrm{E}} \mathrm{x}_{\text {dest }}=\dot{\mathrm{E}} \mathrm{x}_{\text {out,comp }}-\dot{\mathrm{E}} \mathrm{x}_{\mathrm{in}, \mathrm{comp}}
$$

where difference between minimum required power to be supplied to the compressor (useful work) is $\dot{\mathrm{W}}_{\text {comp }}$ and the exergy destruction is $\dot{\mathrm{E}} \mathrm{x}_{\text {dest }}$.

\section{RESULTS AND DISCUSSION}

Adana province of Turkey was chosen as the study region. In calculation of the cooling load of the inter-city bus cabin, climate data such as dry bulb temperature, wet bulb temperature and solar radiation of the Adana province were used. The selected bus, which has a passenger capacity of 56 persons, was used for inter-city passenger transportation in the United States and Turkey. Dimensions of the TS 45 type inter-city bus belonging to TEMSA are presented in Figure 2. Dry bulb temperature and wet bulb temperature of outdoor air was accepted as $36.8{ }^{\circ} \mathrm{C}$ and $25.7^{\circ} \mathrm{C}$, respectively. The inter-city bus cabin was maintained at $24.4^{\circ} \mathrm{C}$ dry bulb temperature and $50 \%$ relative humidity. It was assumed that the inter-city bus was traveling to north direction at a speed of $120 \mathrm{~km} / \mathrm{h}$ for the cooling load calculation. 
Cooling Load Hourly Analysis Program (HAP) was used to determine hourly cooling load capacity of the intercity bus. Accordingly, maximum cooling load values were computed to be nearly $25-26 \mathrm{~kW}$ and obtained at 17:00, while the minimum values were acquired at times when atmospheric air temperature and solar radiation were low. Maximum cooling load value was obtained as $25.96 \mathrm{~kW}$ at 17:00 in July. It was also the peak cooling load and peak time. Therefore, the energy and exergy analysis of the inter-city bus AC system were made considering the calculated peak load values. The MR value was considered to be between 0.05 and 0.5 . The inter-city bus cabin was considered at $24.4^{\circ} \mathrm{C}$ dry bulb temperature and $50 \%$ relative humidity, while the outside design conditions were obtained $36.8^{\circ} \mathrm{C}$ dry bulb temperature and $25.7^{\circ} \mathrm{C}$ wet bulb temperature. The supplied air to the conditioned space was assumed to be $10{ }^{\circ} \mathrm{C}$ lower than the inside temperature, and thus determined as $14.4^{\circ} \mathrm{C}$.
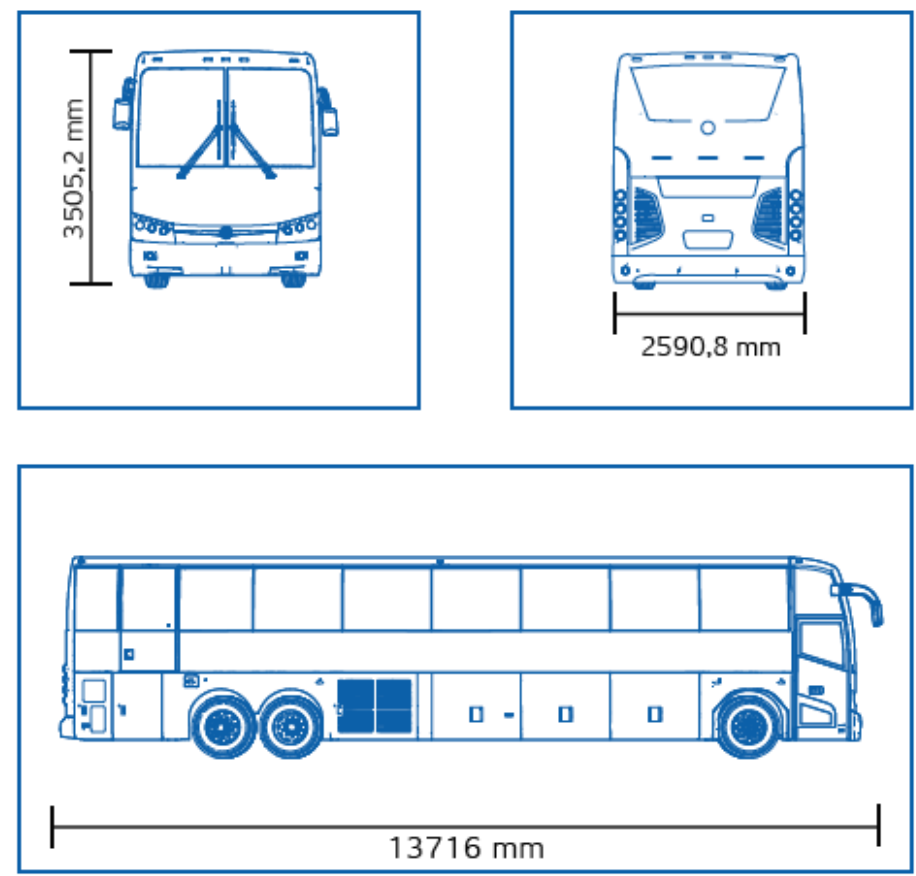

\begin{tabular}{|l|c|c|c|c|c|}
\hline \multicolumn{5}{|c|}{ Dimensions of inter-city bus in mm (TEMSA) } \\
\hline Length & Width & Height & Wheelbase & $\begin{array}{c}\text { Front Exten- } \\
\text { sion }\end{array}$ & Rear Extension \\
\hline 13716 & 2590.8 & 3505.2 & 7894.3 & 1925.3 & 1925.3 \\
\hline \multicolumn{5}{|c|}{ Inter-city bus engine (CUMMINS) } \\
\hline Model & CUMMINS ISX EPA13 345 HP \\
\hline Type & Diesel \\
\hline Number of Cylinders & 6 in line \\
\hline
\end{tabular}

Figure 2. Dimensions of the TS 45 type inter-city bus [6]

The bus sensible cooling load $\left(\dot{\mathrm{Q}}_{\text {sensible,bus }}\right)$ value and the bus latent cooling load value $\left(\dot{\mathrm{Q}}_{\text {latent,bus }}\right)$ were determined as $22.808 \mathrm{~kW}$ and $3.154 \mathrm{~kW}$. The thermodynamic properties of refrigerant R600a were determined using the CoolPack V2.85 software. In the calculations of the refrigeration cycle, value of the evaporation temperature of the refrigerant was considered to be equal to the apparatus dew point temperature. Condensation temperature of the refrigerant was considered to be $15^{\circ} \mathrm{C}$ above the atmospheric air temperature. In addition, superheated and subcooling temperature values were defined as $10^{\circ} \mathrm{C}$. The dead-state temperature $\left(\mathrm{T}_{0}\right)$ was considered to be environment temperature, $36.8^{\circ} \mathrm{C}$. The dead-state pressure $\left(\mathrm{P}_{0}\right)$ was considered to be $101.325 \mathrm{kPa}$.

The effect of MR on COP values of the inter-city bus AC system and the compressor input powers is shown in Figure 3. Maximum useful work and reversible power values were obtained as $9.57 \mathrm{~kW}$ and $8.08 \mathrm{~kW}$ for MR=0.5, while minimum useful work and reversible power were found as $5.62 \mathrm{~kW}$ and $4.73 \mathrm{~kW}$ for $\mathrm{MR}=0.05$, respectively. Determined COP values varied from 5.12 to 5.36 , resulting in up to $4.6 \%$ difference. It was observed that useful work and reversible power increases significantly with increasing MR, thus resulting in reduction in COP. 


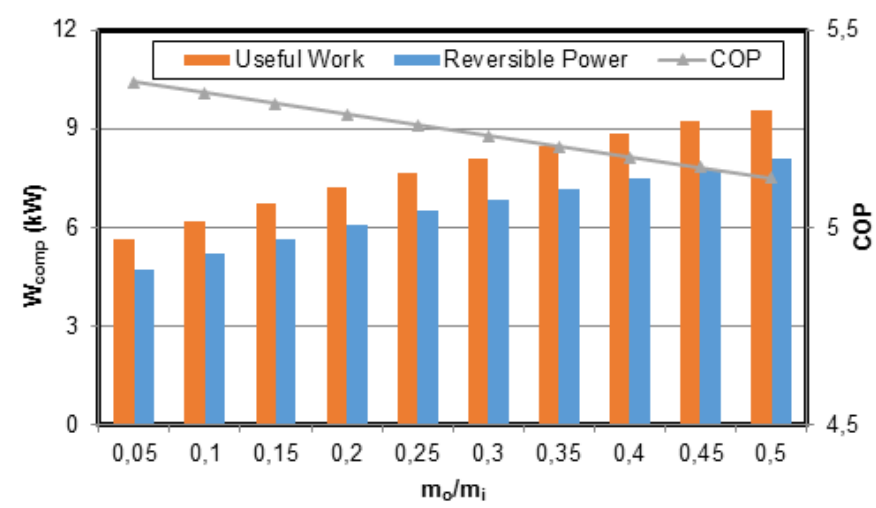

Figure 3. The effect of MR on COP values of the inter-city bus AC system and the compressor input powers

Figure 4 shows the heat transfer rates at condenser and evaporator with respect to MR. As seen from the figure, minimum heat transfer at condenser was observed as $35.79 \mathrm{~kW}$ at $\mathrm{MR}=0.05$, while maximum heat transfer value was calculated as $58.59 \mathrm{~kW}$ at $\mathrm{MR}=0.5$, causing $63.70 \%$ more energy consumption. On the other hand, minimum heat transfer at evaporator was $30.17 \mathrm{~kW}$ and obtained at $\mathrm{MR}=0.05$, while maximum heat transfer at evaporator was $49.03 \mathrm{~kW}$ and obtained at $\mathrm{MR}=0.5$, causing $62.51 \%$ more energy consumption. It is worthwhile to mention that increasing MR causes increment in the temperature and absolute humidity of air mixture. In this regard, it is the main reason for higher heat transfer rates.

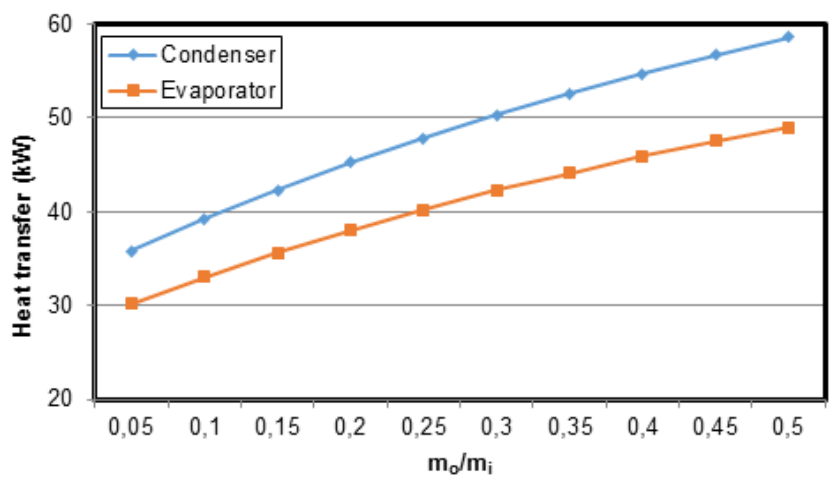

Figure 4. The heat transfer rates at condenser and evaporator with respect to MR

Figure 5 presents exergy destruction values of the inter-city bus AC system equipment with respect to MR for R600a. As presented in the figure, exergy destruction values of each system equipment increases with increasing MR. Maximum exergy destruction values of evaporator, condenser, compressor and expansion valve at $\mathrm{MR}=0.5$ are $2.75 \mathrm{~kW}, 1.87 \mathrm{~kW}$, $1.48 \mathrm{~kW}$ and $0.89 \mathrm{~kW}$, while minimum exergy destruction values of these components at MR=0.05 are $1.15 \mathrm{~kW}, 1.32$ $\mathrm{kW}, 0.88 \mathrm{~kW}$ and $0.51 \mathrm{~kW}$, respectively.

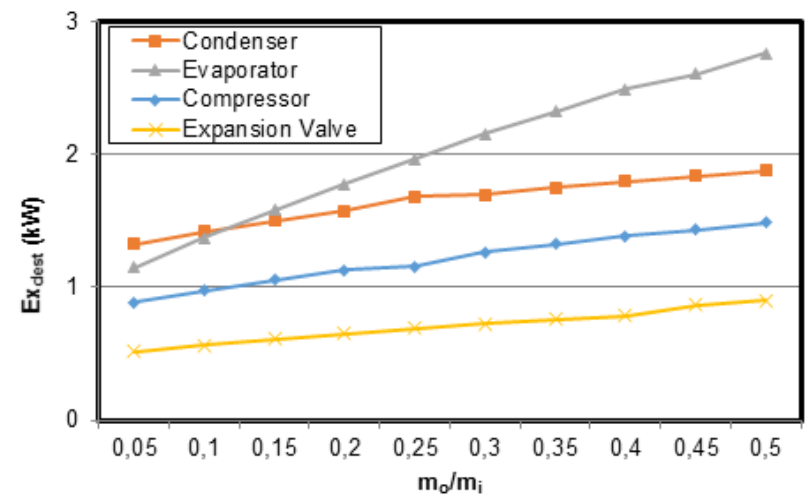

Figure 5. Exergy destruction values of the inter-city bus AC system equipment with respect to MR

Figure 6 shows exergy efficiency values of the inter-city bus AC system equipment with respect to MR. As demonstrated in the figure, exergy efficiency values of the each system component varies indistinctly with respect to MR. Exergy efficiencies of expansion valve, compressor, evaporator and condenser at $\mathrm{MR}=0.5$ are $92.05 \%, 84.46 \%, 74.16 \%$ and $31.43 \%$, whereas exergy efficiencies values at $\mathrm{MR}=0.05$ are $92.52 \%, 84.18 \%, 83.36 \%$ and $19.64 \%$, respectively. It is observed that expansion valve has the highest exergy efficiency values and condenser has the lowest exergy efficiency values for all MR values. 


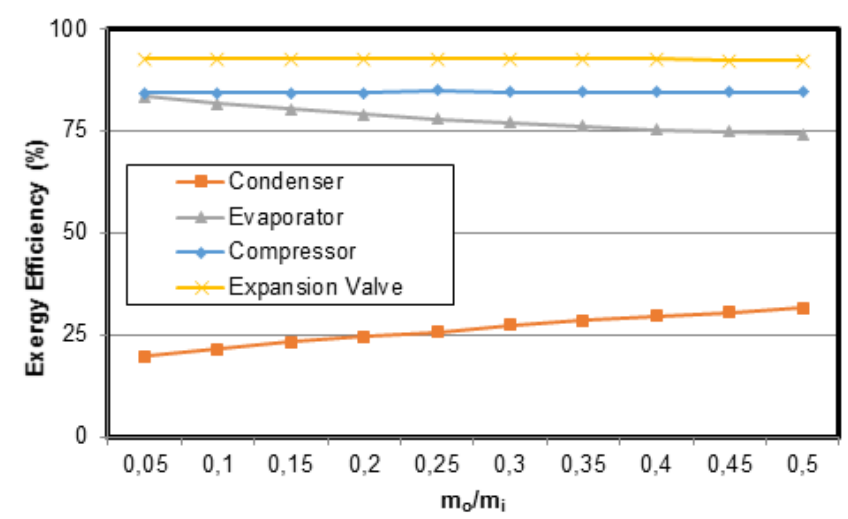

Figure 6. Exergy efficiency values of the inter-city bus AC system equipment with respect to MR

Figure 7 presents overall exergy efficiency and total exergy destruction values of the inter-city bus AC system with respect to MR for R600a. As can be observed from the figure, total exergy destruction values increase significantly in parallel with MR values, while overall exergy efficiency values do not change excessively. Maximum overall exergy efficiency and total exergy destruction are $46.45 \%$ and $7.02 \mathrm{~kW}$, and minimum overall exergy efficiency and total exergy destruction are $45.67 \%$ and $3.88 \mathrm{~kW}$, respectively.

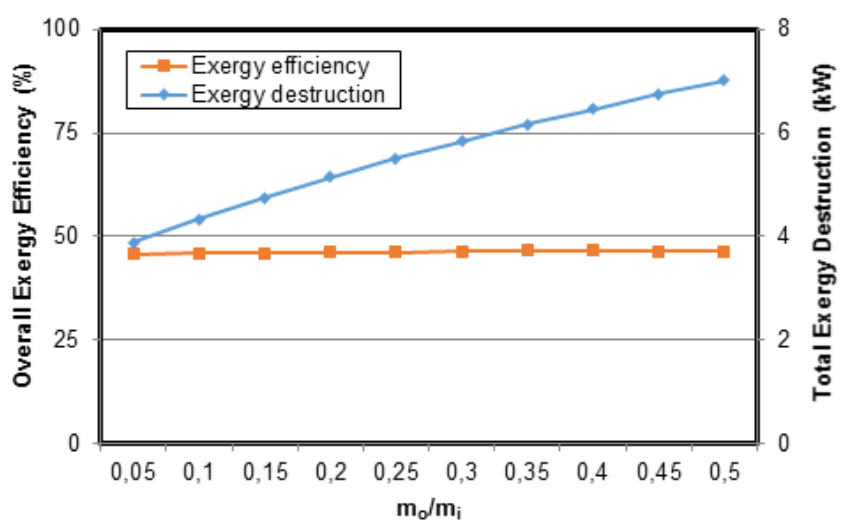

Figure 7. Overall exergy efficiency and total exergy destruction values of the inter-city bus AC system with respect to MR

\section{CONCLUSIONS}

- Total exergy destruction values increase significantly in parallel with MR values,

- Maximum useful work and reversible power values were obtained as $9.57 \mathrm{~kW}$ and $8.08 \mathrm{~kW}$ for $\mathrm{MR}=0.5$, while minimum useful work and reversible power were found as $5.62 \mathrm{~kW}$ and $4.73 \mathrm{~kW}$ for $\mathrm{MR}=0.05$, respectively.

- According to the results for MR=0.5, exergy destruction values of the inter-city bus AC system were calculated to be $1.5 \mathrm{~kW}, 1.88 \mathrm{~kW}, 0.90 \mathrm{~kW}$ and $2.76 \mathrm{~kW}$ for the compressor, condenser, expansion valve and evaporator, respectively.

- Also, exergy efficiency values in these components were respectively found as $84.46 \%, 31.43 \%$, $74.16 \%$ and $92.05 \%$.

- Total exergy destruction and overall exergy efficiency of the system were obtained as $46.45 \%$ and 7.02 $\mathrm{kW}$, respectively.

\section{ACKNOWLEDGEMENTS}

The authors would like to thank to TEMSA Global for its contribution.

\section{REFERENCES}

[1] Bilgili, M., Ozbek, A., Sahin, B., Kahraman, A. (2015). An overview of renewable electric power capacity and progress in new technologies in the World. Renewable and Sustainable Energy Reviews, vol. 49, p. 323-334, DOI: 10.1016/j. rser.2015.04.148. 
[2] Chu, C.M., Jong, T.L. (2008). Enthalpy estimation for thermal comfort and energy saving in air conditioning system. Energy Conversion and Management, vol. 49, no. 6, p. 1620-1628, DOI: 10.1016/j.enconman.2007.12.012.

[3] Weilenmann, M.F., Alvarez, R., Keller, M. (2010). Fuel consumption and $\mathrm{CO}_{2}$ pollutant emissions of mobile air conditioning at fleet level-new data and model comparison. Environmental Science and Technology, vol. 44, no. 13, p. 5277-5282, DOI: $10.1021 /$ es 903654 t.

[4] Tosun, E., Bilgili, M., Tuccar, G., Yasar, A., Aydin, K. (2016). Exergy analysis of an inter-city bus air-conditioning system. International Journal of Exergy, vol. 20, no. 4, p. 445-464, DOI: 10.1504/IJEX.2016.078094.

[5] Hurdogan, E., Buyukalaca, O., Hepbasli, A., Yilmaz, T. (2011). Exergetic modeling and experimental performance assessment of a novel desiccant cooling system. Energy and Buildings, vol. 43, no. 6, p. 1489-1498, DOI: 10.1016/j.enbuild.2011.02.016.

[6] TEMSA. (2016). TS45 - Training Document (Vol. 1). Adana: Temsa Ulaşım Araçları Sanayi ve Ticaret A.Ş. 